\title{
Aprendizagem da leitura e da escrita: o papel das habilidades metalingüísticas
}

\author{
Maria Beatriz Zanarella Cruz'.
}

Guimarães, S. R. K. (2005). Aprendizagem da leitura e da escrita: o papel das habilidades metalingüísticas. (1 $1^{\mathrm{a}}$ ed.). São Paulo: Vetor. 257 p.

O livro escrito por Sandra Regina Kirchner Guimarães é um estudo prático sobre as habilidades metalingüísticas (consciência fonológica e consciência sintática) e sua relação com a aprendizagem da leitura e da escrita e problemas fonológicos. Por se tratar de uma pesquisa, a obra foi organizada tomando como base a seguinte estrutura: introdução teórica; metodologia; apresentação e discussão dos resultados; conclusões e considerações finais e referências bibliográficas.

No que diz respeito ao referencial teórico, o leitor encontra um capítulo subdividido em sete tópicos, cujo tema principal é a dificuldade da aprendizagem da leitura e da escrita. Inicialmente, a autora apresenta uma abordagem histórica das concepções relativas às dificuldades de aprendizagem da leitura e da escrita em que se torna possível identificar diferentes hipóteses explicativas a respeito do assunto e sua conceituação mais recente. O capítulo avança apresentando estudos que relacionam a consciência fonológica e consciência sintática com a aprendizagem da leitura e da escrita associada às habilidades metalingüísticas. Logo após, a autora dá ênfase aos problemas adquiridos durante a aquisição e o desenvolvimento da leitura e da escrita, tomando como base a teoria do processamento da informação. Ao final de cada tópico o leitor encontra um pequeno resumo que favorece uma visão global sobre o assunto abordado.

A segunda parte do estudo se refere à metodologia adotada por Guimarães para investigar a relação entre o nível de habilidades metalingüísticas e as diferenças de desempenho na leitura e na escrita. Assim, detalhes sobre o delineamento da pesquisa, informações sobre os sujeitos, os tipos de instrumentos utilizados e o procedimento de análise dos dados encontram-se expostos nessa parte. Tais dados são apresentados numa linguagem simples e objetiva, propiciando ao leitor fácil compreensão do método utilizado para a realização do trabalho.

$\mathrm{Na}$ terceira parte, que se refere à apresentação e discussão dos resultados, a autora discute os dados obtidos na pesquisa, indicando que as dificuldades de aprendizagem da linguagem escrita estão relacionadas predominantemente com problemas de natureza fonológica. $\mathrm{Na}$ quarta parte, intitulada conclusões e considerações finais, ela retoma, de forma resumida, todo o estudo desenvolvido, descrevendo o conteúdo dos capítulos abordados no corpo teórico do trabalho, e ressalta algumas implicações educacionais da presente pesquisa. Como conclusão, Guimarães sugere que a intervenção pedagógica nos sujeitos com dificuldades de leitura e escrita deve privilegiar atividades que possam promover o desenvolvimento da consciência fonológica. Por fim, o leitor tem acesso às referências consultadas para o desenvolvimento do trabalho, as quais são, em sua maioria, estrangeiras e provenientes de artigos científicos.

Esse livro oferece informações enriquecedoras referentes aos conceitos e aos processos que envolvem a aprendizagem da leitura e da escrita, sendo indicado para os profissionais e pesquisadores da área. Oferece também uma bibliografia complementar que contribui para que os leitores interessados possam buscar por outras referências associadas ao assunto em questão.

Sobre a autora:

Maria Beatriz Zanarella Cruz é psicóloga e mestranda em Psicologia pela Universidade São Francisco.

\footnotetext{
${ }^{1}$ Endereço para correspondência:

Universidade São Francisco - Programa de Pós-Graduação em Psicologia

Rua Alexandre Rodrigues Barbosa, 45 - 13251-040 - Itatiba-SP
} 
